\title{
Deposição e deriva de calda fungicida aplicada em feijoeiro, em função de bico de pulverização e de volume de calda
}

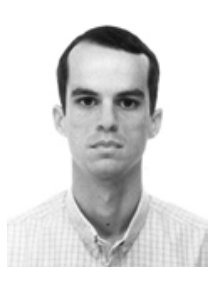

João P. A. R. da Cunha' ${ }^{1}$, Mauri M.Teixeira' ${ }^{2}$, Rogério F. Vieira ${ }^{3}$ \& Haroldo C. Fernandes ${ }^{2}$

1 UEG/UNUCET, Br. 153, km 98, CEP 75110-390, Anápolis, Go. Fone: (62) 328 1181. E-mail: jparc@bol.com.br (Foto)
2 DEA/UFV, CEP 36571-000, Viçosa, MG. Fone: (31) 3899 1878. E-mail: mauri@ufv.br; haroldo@ufv.br
${ }^{3}$ EPAMIG/EMBRAPA, CEP 36571-000, Viçosa, MG. Fone: (31) 3891 2646. E-mail: rfvieira@epamig.ufv.br

Protocolo 172 - 23/10/2003 - Aprovado em 17/3/2004

\begin{abstract}
Resumo: A tecnologia de aplicação de agrotóxicos visa à colocação uniforme do produto no alvo, com mínima perda por escorrimento e deriva. Este trabalho teve como objetivo avaliar a deposição e a deriva de calda fungicida pulverizada em feijoeiro com diferentes bicos e volumes de aplicação. Empregou-se o delineamento em blocos ao acaso, com quatro repetições, em esquema fatorial $(2 \times 2)$ : dois tipos de bico de pulverização (jato plano standard e jato cônico vazio) e dois volumes de aplicação (125 e $\left.250 \mathrm{~L} \mathrm{ha}^{-1}\right)$. O estudo de deposição foi realizado analisando-se a distribuição de um traçador nas posições superior e inferior da planta, pela técnica da espectrofotometria, enquanto a deriva foi avaliada utilizando-se de alvos artificiais, posicionados fora da área-alvo. O fungicida, juntamente com o traçador, foi aplicado três vezes, com um pulverizador de pressão constante $\left(\mathrm{CO}_{2}\right)$. Os bicos propiciaram cobertura semelhante da folhagem do feijoeiro, tanto na posição superior quanto na inferior do dossel. O volume de aplicação de $250 \mathrm{~L} \mathrm{ha}^{-1}$ proporcionou maior retenção de calda na folhagem e maior uniformidade de cobertura das plantas que o volume de $125 \mathrm{~L} \mathrm{ha}^{-1}$; já as gotas formadas nas aplicações com bicos de jato cônico vazio ficaram mais sujeitas à deriva que as produzidas com bicos de jato plano, especialmente quando se empregou baixo volume de aplicação. As aplicações realizadas proporcionaram, em geral, baixa uniformidade de deposição ao longo do dossel do feijoeiro e risco potencial de deriva elevado.
\end{abstract}

Palavras-chave: tecnologia de aplicação, agrotóxicos, Phaseolus vulgaris L.

\section{Deposition and drift of fungicide application in a bean crop influenced by spray volumes and nozzles}

\begin{abstract}
The fungicide application technology should provide efficient control of vegetable diseases. The objective of this study was to evaluate the deposition and the drift of fungicide sprayed in a common bean crop with different nozzles and two volumes of application. A completely randomized block design with four replications was used, in a factorial model $2 \times 2$ : two spray nozzles (standard flat fan and hollow cone) and two spray volumes (125 and $250 \mathrm{~L} \mathrm{ha}{ }^{-1}$ ). The study of deposition was made by a tracer analysis in different positions of the crop, using spectrophotometer. The drift was evaluated using artificial targets placed outside the application area. The fungicide, with the tracer was applied three times, using a $\mathrm{CO}_{2}$ - pressurized sprayer. The results allowed the following conclusions: the flat fan and hollow cone nozzles provided similar cover of the bean leaves, both in the superior and the inferior position of the crop; the application volume of $250 \mathrm{~L} \mathrm{ha}^{-1}$ provided higher retention of fungicide in the leaves and higher uniformity of coverage of the plants than the volume of $125 \mathrm{~L} \mathrm{ha}^{-1}$; the droplets formed in the application with hollow cone nozzles were more favorable to the drift than the ones produced with flat fan nozzles, specially when low application volume was used; and the applications, in general, provided low deposition uniformity and high drift potential.
\end{abstract}

Key words: application technology, pesticide, Phaseolus vulgaris L. 


\section{INTRODUÇÃO}

O feijão é um dos produtos agrícolas brasileiros de maior importância social e econômica. A produção nacional está em torno de 2,9 milhões de toneladas, com área colhida de 4,3 milhões de hectares e produtividade média de $684 \mathrm{~kg} \mathrm{ha}^{-1}$ (FNP, 2002).

Apesar das práticas culturais se estarem modernizando nos últimos anos, a produtividade atual ainda se acha muito aquém do potencial da cultura, que é superior a $4.500 \mathrm{~kg} \mathrm{ha}^{-1}$. Uma das causas dessa baixa produtividade é a ocorrência de doenças. Estima-se em $10 \%$ as perdas anuais na produtividade do feijoeiro, ocasionadas por fitopatógenos (Hall, 1994).

Uma alternativa para contornar o problema é a aplicação de fungicidas, que diminuem a severidade das doenças e podem aumentar a produtividade da cultura (Dudienas et al., 1990). A forma tradicional de aplicação desses produtos é por meio de pulverizadores dotados de bicos de pulverização hidráulicos. Esses bicos são os componentes mais significativos dos pulverizadores e apresentam, como funções básicas: fragmentar o líquido em pequenas gotas, distribuir as gotas em pequena área e controlar a saída do líquido por unidade de área (Sidahmed, 1998).

Para a aplicação de fungicidas nos feijoeiros, os bicos mais utilizados são os de jato cônico vazio mas, em virtude do seu espectro de gotas propiciar a deriva, tem-se tentado utilizar também os de jato plano. Estes, no entanto, podem comprometer a cobertura das plantas, em razão das gotas serem de maior tamanho. Conseqüentemente, poderá haver menor controle de doenças. De forma geral, gotas pequenas são facilmente transportadas pelo vento porém propiciam maior cobertura do alvo, condição desejada sobretudo quando da utilização de defensivos de contato. Segundo Sumner \& Sumner (1999), a deriva é um dos maiores problemas da aplicação de agrotóxicos, a qual pode causar ineficiência da aplicação e contaminação ambiental.

Outra variável importante na aplicação de fungicidas é o volume de aplicação; prática comum era se aplicar volumes superiores a $300 \mathrm{~L} \mathrm{ha}^{-1}$; atualmente, entretanto, existe tendência a se reduzir o volume de calda, visando diminuir os custos de aplicação e aumentar a eficiência da pulverização (Silva, 1999). $\mathrm{O}$ uso de menor volume de calda aumenta a autonomia e a capacidade operacional dos pulverizadores.

A redução do volume de calda requer, porém, um aprimoramento da tecnologia de aplicação empregada no campo. Segundo Salyani (1999), a redução do orifício de saída dos bicos, para obter menor volume de aplicação, aumenta o risco de deriva em virtude da diminuição do tamanho das gotas geradas. O problema se agrava quando se leva em conta que bicos de jato cônico vazio, por trabalharem em pressões mais elevadas que os bicos de jato plano, tendem a produzir gotas com menor diâmetro, razão por que há maior possibilidade de contaminação ambiental com a utilização dos bicos de jato cônico vazio (Srivastava et al., 1994). Uma maneira de se reduzir a deriva consiste em aumentar o diâmetro das gotas e diminuir a proporção de gotas menores que $100 \mu \mathrm{m}$, o que é possível com o uso de bicos de jato plano (Jensen et al., 2001). Em geral, gotas menores são mais eficazes no combate a pragas e doenças mas pouco seguras, sob o ponto de vista ambiental. Assim, há necessidade de estudos que viabilizem e otimizem a redução do volume de aplicação nas pulverizações de fungicidas, para permitir a utilização de bicos e volumes de calda adequados (Silva, 1999).

Os resultados das aplicações em lavouras podem ser altamente variáveis. Em geral, o grau de sucesso é determinado pela intensidade e uniformidade da cobertura. A eficácia do tratamento depende não apenas da quantidade de material depositado sobre a vegetação mas, também, da uniformidade de cobertura do alvo (McNichol et al., 1997). Para a avaliação em campo dos tratamentos fitossanitários, adotam-se critérios baseados na análise de distribuição do produto sobre a cultura. Os métodos usuais são baseados em análise visual, mensuração óptica e análises químicas (Salyani \& Whitney, 1988). Técnicas como fluorimetria (Cunningham \& Harden, 1999), espectrofotometria (Derksen \& Sanderson, 1996) e cromatografia (Cunha, 2000) podem ser encontradas na literatura. A análise visual é um método rápido e fácil, mas de pouca precisão, enquanto os métodos que envolvem análises químicas e analisadores de imagens são mais precisos. Hewitt (2000) apresenta uma revisão das metodologias para a quantificação de deposição e deriva nas aplicações em campo. Entre os métodos modernos de análise, a espectrofotometria ocupa lugar de destaque, devido a facilidade em determinar quantidades diminutas de substâncias (Vogel, 1992).

Estudos sobre padrões de deposição de pulverizações indicam grande variabilidade de deposição dos agrotóxicos ao longo das faixas de aplicação, o que diminui a eficácia dos tratamentos (Coates \& Palumbo, 1997; Gupta \& Duc, 1996 e Pergher et al., 1997). De maneira geral, a deposição é menor nas partes mais baixas e internas do dossel das culturas. No caso de fungicidas, esta desuniformidade proporciona baixa eficácia no controle das doenças, principalmente no caso de fungicidas de contato, que requerem cobertura uniforme de toda a planta. Este problema se acentua nas aplicações em que se utilizam bicos de jato plano que, em geral, produzem menor número de gotas por área e menor turbulência.

Este trabalho teve como objetivo avaliar a deposição e a deriva de calda fungicida pulverizada no feijoeiro com bicos de jato plano e de jato cônico vazio, em diferentes volumes de pulverização.

\section{MATERIAL E MÉTODOS}

O presente estudo foi conduzido na Universidade Federal de Viçosa, no Laboratório de Qualidade da Água do Departamento de Engenharia Agrícola, e em campo, durante a estação de inverno de 2002, em área experimental do Departamento de Fitotecnia, município de Coimbra, MG, na altitude de $716 \mathrm{~m}$, longitude de $42^{\circ} 48^{\prime} \mathrm{S}$ e latitude de $20^{\circ} 51^{\prime} \mathrm{W}$. Também foram realizadas análises de espectro de gotas no Laboratório de Controle Ambiental da Universidade Federal de São Carlos.

Inicialmente, foi realizada em laboratório, como complemento às avaliações de deposição e deriva, a análise do espectro de gotas produzidas pelos mesmos bicos e pressões empregadas no campo. Para isto, fez-se uso de um analisador a laser de 
gotas em tempo real (Spraytec, Malvern Instruments). Determinou-se o diâmetro da mediana volumétrica (DMV) e a porcentagem de volume composto por gotas com diâmetro inferior a $100 \mu \mathrm{m}$, de acordo com a metodologia apresentada pela ASAE (2000).

Em campo, utilizou-se a cultivar de feijão do tipo carioca Pérola, semeada no espaçamento entre fileiras de $0,50 \mathrm{~m}$, com cerca de 15 sementes $\mathrm{m}^{-1}$. Esta cultivar foi lançada em 1996 e é uma das mais semeadas no País. Apesar do porte semi-prostrado (tipo III), produz ramas na parte superior da planta, que se entrelaçam, evitando o tombamento excessivo.

O ensaio foi conduzido no delineamento em blocos ao acaso, com quatro repetições, em esquema fatorial $(2 \times 2)$. Avaliaramse, considerando-se a deposição e a deriva, dois tipos de bico de pulverização (jato plano e jato cônico vazio) e dois volumes de aplicação (125 e $\left.250 \mathrm{~L} \mathrm{ha}^{-1}\right)$ durante a aplicação de fungicida no feijoeiro.

Utilizaram-se bicos de pulverização hidráulicos fabricados em alumina revestida por poliacetal: API 110-02, API 110-04, ATR Brown e ATR Red (todos fabricados pela Albuz, Ceramiques Techniques Desmarquest, Evreux, France). Os bicos de jato plano API (alumina plástico ISO) são de uso geral e, de acordo com o fabricante, proporcionam aplicações uniformes quando os jatos de pulverização se sobrepõem; são recomendados para trabalhar em pressões entre 200 e $400 \mathrm{kPa}$, com altura mínima da barra porta-bicos de $40 \mathrm{~cm}$ em relação ao alvo. Os bicos de jato cônico vazio ATR (alumina turbulência) são indicados para aplicações de fungicidas e inseticidas com pressão superior a $300 \mathrm{kPa}$, em barras de pulverização.

A velocidade de deslocamento do aplicador foi de $4 \mathrm{~km} \mathrm{~h}^{-1}$, quando se utilizou o bico ATR Brown, e de $6 \mathrm{~km} \mathrm{~h}^{-1}$ para os demais. A pressão do líquido durante a operação foi de $200 \mathrm{kPa}$ para os bicos de jato plano e de $400 \mathrm{kPa}$ para os bicos de jato cônico. Esses valores de pressão e velocidade foram empregados para atingir os dois volumes de aplicação selecionados: 125 e $250 \mathrm{~L} \mathrm{ha}^{-1}$.

Utilizou-se o fungicida de contato chlorothalonil na formulação pó-molhável, na dose recomendada pelo fabricante (1,5 $\mathrm{kg} \mathrm{ha}^{-1}$ do ingrediente ativo). Ele foi aplicado três vezes: aos 20, 30 e 40 dias após a emergência. Para a aplicação, utilizouse um pulverizador costal de pressão constante $\left(\mathrm{CO}_{2}\right)$, dotado de uma barra porta-bicos de $2 \mathrm{~m}$. A altura da barra em relação à cultura e o espaçamento entre bicos foram de $0,5 \mathrm{~m}$.

Para o estudo de deposição da calda pulverizada, analisouse a distribuição de fungicida sobre o feijoal, por meio da quantificação de um traçador, adicionado à calda, nas folhas, em duas posições na planta, conforme metodologia apresentada por Palladini (2000). A deposição do traçador, utilizando-se baixo volume de calda $\left(125 \mathrm{~L} \mathrm{ha}^{-1}\right)$, foi comparada com a deposição em que se empregou volume de calda tradicional $\left(250 \mathrm{~L} \mathrm{ha}^{-1}\right)$. Da mesma forma, a deposição, empregando-se bicos de jato plano, foi comparada com aquela em que foram utilizados bicos de jato cônico vazio.

Para a avaliação da deposição, lançou-se mão de um traçador composto do corante alimentício azul brilhante (Corante Azul FCF, Duas Rodas Industrial), catalogado internacionalmente pela "Food, Drug \& Cosmetic" como FD\&C Blue n.1. O corante foi utilizado na concentração de $1.500 \mathrm{mg} \mathrm{L}^{-1}$ para volumes de aplicação de $125 \mathrm{~L} \mathrm{ha}^{-1}$, e de $750 \mathrm{mg} \mathrm{L}^{-1}$ para volumes de aplicação de $250 \mathrm{~L} \mathrm{ha}^{-1}$. Ele foi detectado por absorbância em espectrofotometria, que consiste na determinação da concentração de uma substância pela medida da absorção relativa da luz. Utilizou-se um espectrofotômetro Coleman 33D (fotômetro fotelétrico de filtro) com lâmpada de tungstêniohalogênio.

Após a aplicação, foram marcadas dez plantas, escolhidas ao acaso em cada parcela e, em cada planta, coletaram-se dois folíolos centrais, um na parte superior e outro na parte inferior da planta colocando-os, então, em recipientes plásticos, adicionando-lhes $100 \mathrm{~mL}$ de água destilada. Esses recipientes foram fechados, agitados por $30 \mathrm{~s}$ e conservados ao abrigo da luz. Posteriormente, fez-se a quantificação da coloração por absorbância em $630 \mathrm{~nm}$ (faixa de detecção do corante azul utilizado). Os folíolos tiveram sua área medida por meio de digitalização e análise no programa computacional "Image Tool" versão 3.0.

Com o uso da curva de calibração, obtida por meio de soluções-padrão, os dados de absorbância foram transformados em concentração $\left(\mathrm{mg} \mathrm{L}^{-1}\right) \mathrm{e}$, de posse da concentração inicial da calda e do volume de diluição das amostras, determinou-se o volume retido no alvo; procedeuse, então, à divisão do depósito total pela área foliar de remoção obtendo-se, assim, a quantidade em $\mu \mathrm{L} \mathrm{cm}^{-2}$ de folha.

A avaliação da deriva se deu durante as aplicações do traçador no feijoeiro. Utilizaram-se alvos artificiais, etiquetas de papel sensível à água, do mesmo modo que foi feito por Wolf \& Frohberg (2002) e Sumner \& Sumner (1999). As etiquetas foram colocadas a $1 \mathrm{~m}$ de altura fora da área-alvo de aplicação, a 5, 10 e $15 \mathrm{~m}$ de distância da bordadura, no sentido de deslocamento do vento. Após a aplicação, procedeu-se à contagem dos pontos de impacto em cada etiqueta ( $26 \times 76$ $\mathrm{mm}$ ), que foram indicativos da intensidade de deriva de cada tratamento.

Durante as aplicações foram monitoradas a velocidade do vento, a umidade relativa e a temperatura do ar. As aplicações foram feitas às seis horas da manhã, buscando-se condições climáticas mais propícias.

A parcela experimental foi de $10 \mathrm{~m}^{2}(5 \times 2 \mathrm{~m})$, ou seja, quatro fileiras de $5 \mathrm{~m}$ de comprimento; os dados obtidos foram submetidos à análise de variância e as médias comparadas pelo teste F.

\section{RESULTADOS E DISCUSSÃO}

Na Tabela 1 são mostradas as médias do diâmetro da mediana volumétrica (DMV) e da percentagem do volume pulverizado composto por gotas, com diâmetro inferior a 100 $\mu \mathrm{m}$, correspondentes aos tratamentos realizados em campo para a avaliação de deriva e deposição. $\mathrm{O}$ menor volume de aplicação e, especialmente, os bicos de jato cônico vazio, propiciaram gotas de menor tamanho e, em conseqüência, com maior risco potencial de serem arrastadas pelo vento.

As condições climáticas ocorridas em campo durante as três aplicações do fungicida são apresentadas na Tabela 2 . Notam-se condições diferenciadas em cada aplicação, mas tais condições foram, de forma geral, adequadas às aplicações: 
Tabela 1. Médias de diâmetro da mediana volumétrica (DMV) e de percentagem do volume pulverizado composto por gotas com diâmetro (\%VGD) inferior a $100 \mu \mathrm{m}$, em função de bicos e volumes de aplicação (ensaio em laboratório*)

\begin{tabular}{|c|c|c|c|c|}
\hline \multirow{3}{*}{ Bico } & \multicolumn{2}{|c|}{$\operatorname{DMV}(\mu \mathrm{m})$} & \multicolumn{2}{|c|}{$\% \mathrm{VGD}<100 \mu \mathrm{m}$} \\
\hline & \multicolumn{2}{|c|}{ Vol. de Aplicação $\left(\mathrm{L} \mathrm{ha}^{-1}\right)$} & \multicolumn{2}{|c|}{ Vol. de Aplicação $\left(\mathrm{L} \mathrm{ha}^{-1}\right)$} \\
\hline & 125 & 250 & 125 & 250 \\
\hline Jato Plano & 164 & 214 & 15,71 & 11,32 \\
\hline Jato Cônico & 90 & 129 & 54,93 & 35,27 \\
\hline
\end{tabular}

* A pressão de operação foi de $200 \mathrm{kPa}$ para os bicos de jato plano e de $400 \mathrm{kPa}$ para os bicos de jato cônico

Tabela 2. Velocidade do vento (VV), umidade relativa (UR) e temperatura do ar (Temp.), durante as três aplicações de fungicida no feijoeiro

\begin{tabular}{cccc}
\hline Aplicação & VV $\left(\mathrm{m} \mathrm{s}^{-1}\right)$ & UR $(\%)$ & Temp. $\left({ }^{\circ} \mathrm{C}\right)$ \\
\hline 1 & $2,0-3,0$ & $85,0-95,0$ & $25,0-28,0$ \\
2 & $1,5-2,5$ & $75,0-90,0$ & $18,0-26,0$ \\
3 & $0,7-1,3$ & $75,0-95,0$ & $12,0-22,0$ \\
\hline
\end{tabular}

temperatura inferior a $28{ }^{\circ} \mathrm{C}$, umidade relativa superior a $75 \%$ e velocidade do vento entre 1 e $3 \mathrm{~m} \mathrm{~s}^{-1}$.

Na Figura 1 é apresentada a curva de calibração utilizada no estudo de deposição para determinar a concentração do traçador retido nas folhas do feijoeiro. A relação entre absorbância e concentração foi linear até aproximadamente $15 \mathrm{mg} \mathrm{L}^{-1}$. Este resultado é semelhante aos de Palladini (2000).

Na Tabela 3 apresentam-se as médias dos volumes de calda retidos na folhagem do feijoeiro nas partes superior e inferior do dossel, após a pulverização com bicos de jato plano e de jato cônico vazio em dois volumes de pulverização, para as três aplicações distintas.

A interação entre bicos e volumes de aplicação não foi significativa a $5 \%$ de probabilidade pelo teste $\mathrm{F}$, indicando a independência entre os dois fatores. Nas três aplicações não houve diferença significativa entre as médias do volume de calda retido na folhagem, com os bicos de jato plano e de jato cônico vazio, independentemente da posição no dossel, mostrando não haver diferenças entre os dois bicos quanto à deposição.

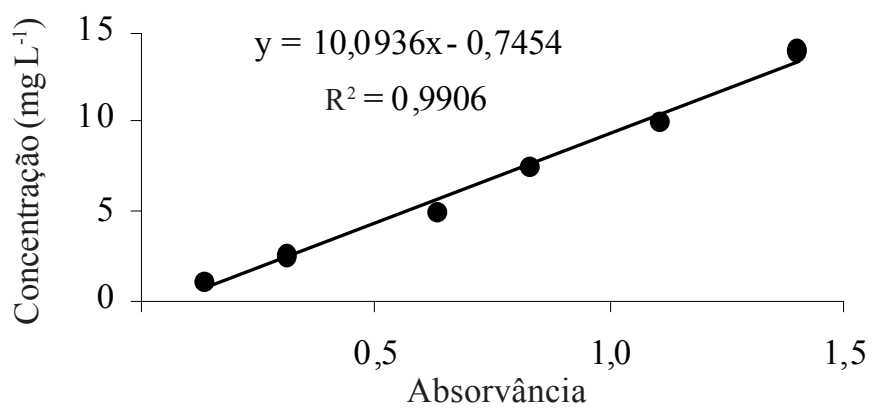

Figura 1. Calibração empregada na determinação da concentração do traçador retido nas folhas do feijoeiro

Esperava-se que bicos que produzissem gotas de menor tamanho, como os de jato cônico vazio, propiciassem maior cobertura do alvo; entretanto, na prática isto não ocorreu. Cross et al. (2001) estudaram a influência da variação do tamanho de gotas (DMV variando de 156 a $237 \mu \mathrm{m}$ ) na deposição de agrotóxicos em alvos naturais. Eles encontraram, também, cobertura do alvo semelhante quando do uso de gotas nessa faixa de diâmetro, devido às perdas das gotas pequenas provocadas por deriva e evaporação. Da mesma forma, Barcellos et al. (1998), estudando a penetração de gotas de pulverização no dossel da cultura da soja, não encontraram superioridade de deposição dos bicos de jato cônico vazio em relação aos bicos de jato plano.

Matthews (1982) afirmou que os bicos de jato cônico vazio são mais eficientes em aplicações sobre folhagens, com relação à cobertura o que, possivelmente, possa ser comprovado quando for considerada a deposição nas partes superior e inferior das folhas de forma separada.

O volume de aplicação de $250 \mathrm{~L} \mathrm{ha}^{-1}$ proporcionou maior retenção de calda nas posições superior e inferior do dossel, nas três aplicações, quando comparado ao volume de $125 \mathrm{~L} \mathrm{ha}^{-1}$. Este resultado indica maior distribuição de calda no alvo empregando-se maior volume de aplicação, condição desejada principalmente quando do uso de agrotóxicos de contato. Em geral, espera-se que o incremento do volume de aplicação propicie aumento do volume de calda retido até certo ponto, a partir do qual a superfície não mais retém o líquido, passando a ocorrer o escorrimento, o que não é desejável. Cross \& Berrie (1993) avaliaram, em túnel de vento, a influência do volume de

Tabela 3. Volume de calda retido na folhagem do feijoeiro ( $\mu \mathrm{L} \mathrm{cm}^{-2}$ de folha) nas partes superior e inferior do dossel, após as aplicações de fungicida com bicos de pulverização de jato plano e de jato cônico vazio, em dois volumes de aplicação*

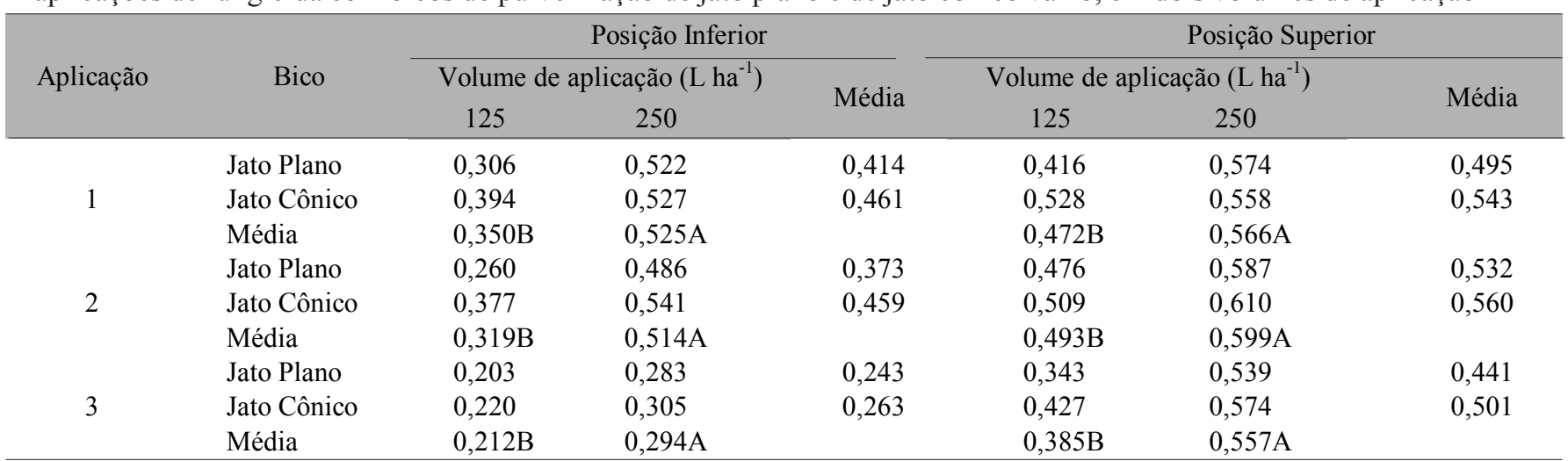

* Médias seguidas por letras distintas, nas linhas, diferem significativamente entre si, a 5\% de probabilidade, pelo teste $\mathrm{F}$ 
aplicação $\left(50,100\right.$ e $\left.200 \mathrm{~L} \mathrm{ha}^{-1}\right)$ na deposição da calda pulverizada e também encontraram maior cobertura do alvo empregando maiores volumes de aplicação.

A diferença percentual de volume retido entre as posições superior e inferior do dossel em relação ao volume retido na posição superior (Tabela 4) dá indicação da uniformidade de deposição, que não foi homogênea, pois ocorreu diferença de retenção ao longo do dossel das plantas. Nas três aplicações não se constatou efeito significativo dos bicos; vários autores, entretanto, citam que os bicos de jato cônico vazio proporcionam cobertura maior e mais homogênea do alvo (Matthews, $1982 \mathrm{e}$ Christofoletti, 1991). Nesse estudo, possivelmente a pressão do líquido empregada nos bicos de jato cônico não tenha sido suficiente para gerar a turbulência necessária à maior penetração do jato pulverizado no dossel das plantas; além disso, a deriva das gotas pequenas também deve ter contribuído para o resultado apresentado.

Tabela 4. Diferença percentual de volume retido entre as posições superior e inferior do dossel do feijoeiro em relação ao volume retido na posição superior, após as aplicações de fungicida com bicos de pulverização de jato plano e de jato cônico vazio, em dois volumes de aplicação*

\begin{tabular}{cllll}
\hline \multirow{2}{*}{ Aplicação } & \multirow{2}{*}{ Bico } & \multicolumn{2}{c}{ Volume de aplicação $\left(\mathrm{L} \mathrm{ha}^{-1}\right)$} & \multirow{2}{*}{ Média } \\
\cline { 3 - 4 } & & 125 & 250 & \\
\hline \multirow{2}{*}{1} & Jato Plano & 26,4 & 9,1 & 17,8 \\
& Jato Cônico & 25,4 & 5,6 & 15,5 \\
& Média & $25,9 \mathrm{~A}$ & $7,3 \mathrm{~B}$ & \\
\multirow{2}{*}{2} & Jato Plano & 45,4 & 17,2 & 31,3 \\
& Jato Cônico & 25,9 & 11,3 & 18,6 \\
& Média & $35,7 \mathrm{~A}$ & $14,3 \mathrm{~B}$ & \\
\multirow{2}{*}{3} & Jato Plano & 40,8 & 47,5 & 44,2 \\
& Jato Cônico & 48,5 & 46,9 & 47,7 \\
& Média & 44,6 & 47,2 & \\
\hline
\end{tabular}

* Médias seguidas por letras distintas, nas linhas, diferem significativamente entre si, a $5 \%$ de probabilidade, pelo teste $\mathrm{F}$

Nas primeira e segunda aplicações, os volumes de aplicação proporcionaram diferença de volume retido entre posições significativamente diferente. O volume de aplicação de 125 $\mathrm{L} \mathrm{ha}^{-1}$ originou maior diferença de volume retido entre posições, indicando menor uniformidade de deposição de calda na planta.

Derksen \& Sanderson (1996) avaliaram a influência do volume de calda na deposição foliar de agrotóxicos e verificaram, com o uso de altos volumes de aplicação, melhor cobertura e menores variações de deposição ao longo do dossel. Os autores explicaram que altos volumes permitem uma redistribuição de produto por meio do escorrimento da parte superior para a parte inferior, o que causa maior deposição nas partes inferiores e, com isso, maior uniformidade de deposição. No entanto, essas aplicações apresentam maiores riscos de contaminação do solo, em virtude da possibilidade da nãoretenção de produto nas folhas.

$\mathrm{Na}$ Tabela 5 tem-se os resultados dos efeitos de bicos e volumes de aplicação sobre as densidades de gotas depositadas a 5,10 e $15 \mathrm{~m}$ de distância da área-alvo. A interação entre bicos e volumes de aplicação foi significativa.

No caso dos bicos de jato cônico vazio, a maior densidade de gotas depositadas fora da área-alvo foi obtida com o menor volume de aplicação. As pontas utilizadas nas aplicações com $125 \mathrm{~L} \mathrm{ha}^{-1}$, por apresentarem orifício de saída menor, produziram gotas de menor tamanho, mais sujeitas à deriva. Quanto ao bico de jato plano, não houve diferença significativa entre os volumes de aplicação, mas sim, ligeira tendência de redução da deriva com o aumento do volume aplicado em todas as distâncias da área-alvo. Avaliando diferentes bicos em volumes de aplicação de 47 e $97 \mathrm{~L} \mathrm{ha}^{-1}$, Wolf \& Frohberg (2002) também encontraram maior intensidade de deriva com menores volumes de calda.

A pulverização com os bicos de jato cônico vazio propiciou maior deposição de gotas fora da área-alvo, em relação aos bicos de jato plano. Os bicos de jato cônico vazio produzem grande volume de gotas com diâmetro inferior a $100 \mu \mathrm{m}$, as quais são mais sujeitas à deriva; além disso, a turbulência gerada por esses bicos, que ora auxilia a penetração do jato no dossel das plantas, também pode provocar efeito oposto: quando a folhagem densa impede a entrada das gotas, o movimento do ar provoca a suspensão delas, que ficam mais sujeitas aos fenômenos climáticos. Christofoletti (1991) também constatou o risco potencial de deriva das aplicações de agrotóxicos com esse tipo de bico.

A intensidade de deriva variou nas três aplicações devido, provavelmente, às condições climáticas de cada aplicação. Constatou-se maior intensidade de ventos na primeira aplicação, enquanto a menor intensidade se deu na terceira aplicação (Tabela 1). Desta forma, já se esperava que os valores de densidade de gotas depositadas fora da área-alvo fossem

Tabela 5. Densidade de gotas (gotas $\mathrm{cm}^{-2}$ ) depositadas em alvos artificiais, obtida durante as aplicações de fungicida com bicos de pulverização de jato plano e de jato cônico vazio, em dois volumes de aplicação, em três distâncias da área-alvo*

\begin{tabular}{|c|c|c|c|c|c|c|c|}
\hline \multirow{3}{*}{ Aplicação } & \multirow{3}{*}{ Bico } & \multicolumn{6}{|c|}{ Distância da Área-Alvo (m) } \\
\hline & & \multicolumn{2}{|c|}{5} & \multicolumn{2}{|c|}{10} & \multicolumn{2}{|c|}{15} \\
\hline & & \multicolumn{6}{|c|}{ Volume de Aplicação $\left(\mathrm{L} \mathrm{ha}^{-1}\right)$} \\
\hline \multirow{2}{*}{1} & Jato Plano & $17,8 \mathrm{Ab}$ & $13,3 \mathrm{Ab}$ & $7,8 \mathrm{Ab}$ & $6,0 \mathrm{Ab}$ & $2,5 \mathrm{Ab}$ & $2,0 \mathrm{Aa}$ \\
\hline & Jato Cônico & $43,5 \mathrm{Aa}$ & $25,5 \mathrm{Ba}$ & $27,8 \mathrm{Aa}$ & $14,0 \mathrm{Ba}$ & 9,3 Aa & $4,5 \mathrm{Ba}$ \\
\hline \multirow{2}{*}{3} & Jato Plano & $4,8 \mathrm{Ab}$ & 5,3Aa & $2,0 \mathrm{Ab}$ & $2,5 \mathrm{Ab}$ & $0 \mathrm{Ab}$ & $0 \mathrm{Ab}$ \\
\hline & Jato Cônico & $14,0 \mathrm{Aa}$ & $8,0 \mathrm{Ba}$ & $9,3 \mathrm{Aa}$ & $5,3 \mathrm{Ba}$ & $1,8 \mathrm{Aa}$ & $1,0 \mathrm{Aa}$ \\
\hline
\end{tabular}


maiores na primeira aplicação e menores na terceira aplicação, fato que reflete bem a importância da escolha do momento ideal para se realizar a aplicação de agrotóxicos.

\section{CONCLUSÕES}

1. Os bicos de jato plano e de jato cônico vazio propiciaram cobertura semelhante da folhagem do feijoeiro, tanto na posição superior quanto na inferior do dossel.

2. O volume de aplicação de $250 \mathrm{~L} \mathrm{ha}^{-1}$ ocasionou maior retenção de calda na folhagem e também maior uniformidade de cobertura das plantas que o volume de $125 \mathrm{~L} \mathrm{ha}^{-1}$.

3. As gotas formadas nas aplicações com bicos de jato cônico vazio estão mais sujeitas à deriva que as produzidas com bicos de jato plano, especialmente quando se emprega baixo volume de aplicação.

4. Em geral, as aplicações realizadas proporcionaram baixa uniformidade de deposição ao longo do dossel do feijoeiro e risco potencial de deriva elevado.

\section{AGRADECIMENTOS}

Ao Conselho Nacional de Desenvolvimento Científico e Tecnológico (CNPq), pelo apoio concedido.

\section{LITERATURA CITADA}

ASAE - American Society of Agricultural Engineering. Spray nozzle classification by droplet spectra. St. Joseph: ASAE, 2000. p.389-391. ASAE Standard S572 AUG99

Barcellos, L.C.; Carvalho, Y.C.; Silva, A.L. Estudo sobre a penetração de gotas de pulverização no dossel da cultura da soja [Glycine max. (L.) Merrill]. Engenharia na Agricultura, Viçosa, MG, v. 6, n. 2, p.81-94, 1998.

Christofoletti, J.C. Bicos de pulverização - seleção e uso. Diadema: Spraying Systems, 1991.9p.

Coates, W.; Palumbo, J. Deposition, off-target movement and efficacy of Capture and Thiodam applied to cantaloupes using five sprayers. Applied Engineering in Agriculture, St. Joseph, v.13, n.2, p.181-188, 1997.

Cross, J.V.; Berrie, A.M. Spray deposits and efficacy of a tunnel sprayer at three volume rates $(50,100,200 \mathrm{~L} / \mathrm{ha})$ in comparison with an axial fan sprayer $(50 \mathrm{~L} / \mathrm{ha})$ on apple. In: International Symposium on Pesticide Application Techniques, 2, 1993, Strasbourg. Proceedings... Strasbourg: BCPC, 1993.p.273-280.

Cross, J.V.; Walklate, P.J.; Murray, R.A.; Richardson, G.M. Spray deposits and losses in different sized apple trees from an axial fan orchard sprayer: 2. Effects of spray quality. Crop Protection, London, v.20, p.333-343, 2001.

Cunha, J.P.A.R. Fungigação: eficácia e uniformidade de distribuição do epoxiconazol, em três lâminas de água, no controle de doenças do feijoeiro. Viçosa: UFV, 2000. 60p. Dissertação Mestrado

Cunningham, G.P.; Harden, J. Sprayers to reduce spray volume in mature citrus trees. Crop Protection, London, v.18, p.275281, 1999.
Derksen, R.C.; Sanderson, J.P. Volume, speed and distribution technique effects on poinsettia foliar deposit. Transactions of the ASAE, St. Joseph, v.39, n.1, p.5-9, 1996.

Dudienas, C.; Castro, J.L.; Ito, M.F.; Soave, J.; Maeda, J.A. Efeito de fungicidas na produção, sanidade e qualidade fisiológica de sementes de feijão. Fitopatologia Brasileira, Brasília, v.15, n. 1, p.20-24, 1990.

FNP. Comércio e Consultoria. Agrianual 2002. São Paulo, 2002. p.345-354.

Gupta, C.P.; Duc, T.X. Deposition studies of a hand-held airassisted electrostatic sprayer. Transactions of the ASAE, St. Joseph, v.39, n.5, p.1633-1639, 1996.

Hall, R. Compendium of beans diseases. St. Paul: APS, 1994. p.71.

Hewitt, A.J. Methodologies for the quantification of spray deposition and drift in field applications. St. Joseph: ASAE, 2000.10p. ASAE Paper n.00-1028

Jensen, P.K.; Jorgensen, L.N.; Kirknel, E. Biological efficacy of herbicides and fungicides applied with low-drift and twinfluid nozzles. Crop Protection, London, v.20, p.57-64, 2001.

Matthews, G.A. Pesticide application methods. London: Longman, 1982.336p.

McNichol, A.Z.; Teske, M.E.; Barry, J.W. A technique to characterize spray deposit in orchard and tree canopies. Transactions of the ASAE, St. Joseph, v.40, n.6, p.1529-1536, 1997.

Palladini, L.A. Metodologia para avaliação da deposição em pulverizações. Botucatu: UNESP, 2000. 111p. Tese Doutorado

Pergher, G.; Gubiani, R.; Tonetto, G. Foliar deposition and pesticide losses from three air-assisted sprayers in a hedgerow vineyard. Crop Protection, London, v.16, p.25-33, 1997.

Salyani, M. Optimization of sprayer output at different volume rates. St. Joseph: ASAE, 1999. 16p. ASAE Paper No. 99-1028

Salyani, M.; Whitney, J.D. Evaluation of methodologies for field studies of spray deposition. Transactions of the ASAE, St. Joseph, v. 31, n. 2, p.390-395, 1988.

Sidahmed, M.M. Analytical comparison of force and energy balance methods for characterizing sprays from hydraulic nozzles. Transactions of the ASAE, St. Joseph, v.41, n.3, p.531-536, 1998 .

Silva, O.C. Tecnologia de aplicação de fungicidas. In: Canteri, M.G.; Pria, M.D.; Silva, O.C. (eds.). Principais doenças fúngicas do feijoeiro. Ponta Grossa: UEPG, 1999. p.127-137.

Srivastava, A.K.; Goering, C.E.; Rohrbach, R.P. Chemical application. In: Engineering principles of agricultural machines, St. Joseph: ASAE, 1994. p.265-324.

Sumner, P.E.; Sumner, S.A. Comparison of new drift reduction nozzles. St. Joseph: ASAE, 1999.17p. ASAE Paper n.99-1156

Vogel, A.I. Análise química quantitativa. 5. ed. Rio de Janeiro: LTC, 1992. 712p.

Wolf, R.E.; Frohberg, D.D. Comparison of drift for four driftreducing flat-fan nozzle types measured in a wind tunnel and evaluated using droplet scan software. St. Joseph: ASAE, 2002, 7p. ASAE Paper n.02-1101 